\title{
La lixiviation d'azote nitrique dans les rotations céréalières avec colza : un diagnostic à partir de l'analyse de résultats d'expérimentations pluriannuelles et de modélisations
}

\author{
Raymond REAU ${ }^{1}$ \\ Alain BOUTHIER ${ }^{2}$ \\ LUC CHAMPOLIVIER ${ }^{3}$ \\ ${ }^{1}$ UMR211 Agronomie, INRA/AgroParisTech, \\ INRA, Thiverval Grignon 78850, France. \\ Fax : 0130815425 \\ <raymond.reau@grignon.inra.fr> \\ 2 ARVALIS-Institut du Végétal, \\ Station du Magneraud, \\ Saint-Pierre d'Amilly 17700, France \\ ${ }^{3}$ CETIOM, Centre de Grignon, \\ Thiverval Grignon 78850, France
}

\begin{abstract}
Nitrate leaching was measured during 6 years in a crop rotation including oilseed rape (OSR) and winter wheat in two field trials, on two rendzina soils differing by their water content, in Le Magneraud (West of France) and Martincourt (East of France). Results show that nitrate losses are variable within the year and drainage: between 20 and $95 \mathrm{kgN} \cdot \mathrm{ha}^{-1} \cdot \mathrm{an}^{-1}$. When the soil remains without cover crop after OSR, losses under wheat following OSR are definitely higher than under OSR following wheat: respectively $54.1 \mathrm{kgN} \cdot \mathrm{ha}^{-1} \cdot \mathrm{an}^{-1}$ and $14.8 \mathrm{kgN} \cdot \mathrm{ha}^{-1} \cdot \mathrm{an}^{-1}$ during the first three years in Le Magneraud. Results even show that nitrate losses differed according to $\mathrm{N}$ strategy management. Among the treatments of nitrogen management, the least losses are observed with optimized fertilization plus OSR volunteers used as cover crop between OSR and wheat; and the highest losses are observed with high fertilization without OSR volunteers as catch crop : respectively in Le Magneraud (second phases of three years) 29.9 and $61.1 \mathrm{kgN} \cdot \mathrm{ha}^{-1}$.an ${ }^{-1}$, and at Martincourt 43.0 and $61.4 \mathrm{kgN} \cdot \mathrm{ha}^{-1} . \mathrm{an}^{-1}$ on average. Simulations realized with LIXIM and DEAC models for new years, soils and regions, show the same trend that experimental results: nitrate losses are higher under wheat after OSR, and the high performance cropping systems are based on optimized $N$ fertilization management of OSR and the catch of nitrate at the end of summer by OSR (after wheat) or its volunteers (before wheat).
\end{abstract}

Key words: Nitrate leaching, oilseed rape, cereal, crop rotation, N fertilisation, catch crop

L'estimation expérimentale des pertes de nitrate est en général assez lourde. Pour mesurer la concentration des eaux et estimer la quantité totale lessivée, on peut utiliser des cases lysimétriques où l'on mesure la lame d'eau drainante et sa concentration en nitrate. Ces dispositifs sont rares et coûteux. Aussi utilise-t-on de plus en plus des méthodes mixtes alliant mesures expérimentales et estimation avec des modèles : soit en utilisant des mesures de concentration d'eau prélevée avec des bougies poreuses couplées avec des mesures du drainage en cases lysimétriques ou avec des estimations issues de calcul de bilan hydrique, soit en utilisant des mesures d'azote minéral dans le sol couplées avec un modèle d'évolution de l'azote dans le sol permettant d'estimer les deux paramètres du lessivage de nitrate.

Ces pertes de nitrate se produisent au moment où la réserve en eau du sol est pleine et où l'essentiel de la pluie non évapotranspirée est évacué du sol par drainage, principalement au cours de l'automne et de l'hiver, c'est-à-dire pendant le début le cycle végétatif de ces cultures d'hiver et pour une grande partie avant le premier apport d'engrais azoté de synthèse.
Compte tenu de la dynamique du nitrate dans le sol, ces pertes dépendent à la fois des reliquats d'azote minéral laissés par la culture précédente, de la minéralisation de l'azote dans le sol et de l'absorption de l'azote par la culture suivante [1]. Dans ces rotations avec culture $d^{\prime}$ 'hiver, il est ainsi hasardeux d'affecter les pertes relevées au cours d'une phase de drainage à une seule de ces cultures. Aussi avons-nous privilégié les dispositifs d'estimation des pertes de nitrate réalisés à l'échelle d'une rotation ou $d^{\prime}$ 'une succession de culture.

\section{Les pertes de nitrate estimées à partir de mesures expérimentales au champ}

Deux stations expérimentales ont mesuré la concentration en nitrate des eaux de drainage sous des parcelles cultivées en rotation colzacéréale. L'une située dans l'ouest, l'autre située dans l'est de la France.

\section{Matériel et méthodes expérimentales}

La succession de cultures qui y a été testée est une rotation courte de deux ans: colza-blé. 
Ces deux dispositifs ont été mis en place dans les petites terres à cailloux calcaires reposant sur du calcaire dur du Jurassique. Le site du Magneraud est situé à proximité de Surgères (Charente maritime), le site de Martincourt à proximité de Nancy (Meurthe et Moselle). Le sol du Magneraud est appelé terre de groie moyenne à profonde: il s'agit d'une rendzine sur calcaire dur, fissuré jusqu'à un mètre de profondeur. Sur un mètre de profondeur colonisable par les racines, la réserve utile en eau de ces sols est estimée à $120 \mathrm{~mm}$. Le climat est caractérisé par un excédent hivernal moyen (P-ETP) de $350 \mathrm{~mm}$, et le drainage mesuré en case lysimétrique dans ces terrains peut varier entre 0 et plus de $500 \mathrm{~mm}$ suivant les années. La station de Martincourt est caractérisée par une rendzine sur calcaire dur fissuré. Sur un mètre de profondeur colonisable par les racines, la réserve utile en eau de ce sol est estimée à $80 \mathrm{~mm}$. Le climat est caractérisé par un excédent hivernal moyen (P-ETP) de 300 mm environ. Le drainage a été estimé par calcul de bilan hydrique entre $103 \mathrm{~mm}$ et $580 \mathrm{~mm}$ au cours de la période 1999-2005.

L'étude réalisée dans ces deux dispositifs a consisté en une expérimentation système [2] dont l'objectif principal n'est pas seulement de tester l'effet d'une technique de gestion de l'azote isolée mais aussi d'évaluer les pertes de l'azote par lessivage générées par un système de culture, caractérisé par une stratégie de gestion de l'azote considérée dans son ensemble. Ces stratégies combinent des niveaux de fertilisation azotée (N1 : fertilisation réduite,
N2: fertilisation raisonnée, N3: fertilisation renforcée), des modes de gestion de l'interculture (SN : sol nu, Rp : repousses de colza), des modalités de travail du sol ( $\mathrm{L}$ : labour, $\mathrm{S}$ : travail sans labour) et des dates de semis du blé ( $P$ : semis précoce, sinon semis à date normale).

À Martincourt, ce sont les mêmes systèmes de culture qui ont été déroulés pendant 6 ans ; tandis qu'au Magneraud une série de systèmes de culture a été testée pendant une première phase de 3 ans, et une nouvelle série de systèmes de culture a été testée pendant une deuxième phase de 3 ans. Les modalités caractérisant la stratégie de gestion de l'azote varient suivant le niveau de fertilisation et le travail du sol en phase 1 du Magneraud, et suivant la fertilisation azotée, la couverture du sol en interculture, la date de semis du blé et le travail du sol en phase 2 du Magneraud, enfin suivant la fertilisation azotée et la couverture du sol en interculture à Martincourt.

Les deux cultures de la rotation sont présentes chaque année et pour chaque traitement. Seuls les grains sont récoltés : après la récolte, les pailles sont broyées et incorporées dans le sol. Les mesures de concentration en nitrate ont été réalisées à l'aide de bougies poreuses placées à une profondeur de $100 \mathrm{~cm}$ et à raison de 9 bougies par parcelle au Magneraud et de 7 à Martincourt. Le volume drainé a été mesuré en case lysimétrique au Magneraud, et estimé par calcul d'un bilan hydrique à Martincourt. Les résultats présentés ici concernent les années 1995-96 à 2000-2001 pour le site du Magneraud, et 1999-2000 à 2004-2005 pour le site de Martincourt. Les modalités, les pratiques de fertilisation et les rendements obtenus figurent dans les tableaux 1 à 3. Au Magneraud, dans une première phase, les fertilisations appliquées sont relativement élevées : plus de 200 unités pour le colza, entre 170 et 190 unités pour le blé en conduite raisonnée ; puis dans une deuxième phase, la fertilisation raisonnée est plus basse pour le colza, entre 180 et 220 unités mais reste semblable pour le blé, entre 170 et 200 unités. Les rendements moyens obtenus par le colza avec ces fertilisations sont très élevés dans la première phase du Magneraud (41 à $43 \mathrm{q} / \mathrm{ha}$ ) mais moyens dans la deuxième phase ( 27 à $34 \mathrm{q} / \mathrm{ha}$ ). Les rendements moyens du blé restent élevés : entre 85 et $87 \mathrm{q} /$ ha durant la première phase, entre 90 et $99 \mathrm{q} /$ ha durant la deuxième phase. À Martincourt, les fertilisations raisonnées moyennes des deux cultures sont comprises entre 170 et 180 unités, mais les rendements sont faibles: en moyenne pluriannuelle 17 à $20 \mathrm{q} / \mathrm{ha}$ de colza et 50 à $55 \mathrm{q} /$ ha de blé. Ces faibles rendements proviennent non seulement d'une réserve utile relativement faible mais aussi d'une difficulté à maîtriser les adventices dans le cadre d'une rotation courte (infestation de brome).

\section{Résultats des dispositifs expérimentaux}

La dynamique des pertes de nitrate est liée au drainage et à la percolation de l'eau dans le profil de ces sols très perméables. Au Magne-

Tableau 1. Modalités de conduite, pratiques de fertilisation et rendements moyens obtenus de 1994-1995 à 1996-1997 au Magneraud. Ce sont les conduites des cultures précédant les cultures sous lesquelles ont été mesurés les nitrates.

\begin{tabular}{|c|c|c|c|c|c|c|c|c|}
\hline Conduite & $\begin{array}{c}\text { Fertilisation } \\
\text { azotée }\end{array}$ & $\begin{array}{c}\text { Interculture } \\
\text { Colza/Blé }\end{array}$ & $\begin{array}{l}\text { Semis } \\
\text { blé }\end{array}$ & $\begin{array}{l}\text { Travail } \\
\text { du sol }\end{array}$ & $\begin{array}{c}\text { Dose azote } \\
\text { colza } \\
\text { kgN/ha }\end{array}$ & $\begin{array}{c}\text { Dose azote } \\
\text { blé } \\
\text { kgN/ha }\end{array}$ & $\begin{array}{c}\text { Rdt moy } \\
\text { colza } \\
\text { q/ha }\end{array}$ & $\begin{array}{c}\text { Rdt moy } \\
\text { blé } \\
\text { q/ha }\end{array}$ \\
\hline N1_SN_L & Réduite & Sol nu & Normal & Labour & 187 & 125 & 39,2 & 74,7 \\
\hline N2_SN_L & Raisonnée & Sol nu & Normal & Labour & 243 & 187 & 41,8 & 86,8 \\
\hline N2_SN_S & Raisonnée & Sol nu & Normal & Superficiel & 247 & 187 & 42,6 & 85,0 \\
\hline N2'_SN_L & Standard & Sol nu & Normal & Labour & 205 & 173 & 42,8 & 85,4 \\
\hline
\end{tabular}

Tableau 2. Modalités de conduite, pratiques de fertilisation et rendements moyens obtenus de 1997-1998 à 1999-2000 au Magneraud. Ce sont les conduites des cultures précédant les cultures sous lesquelles ont été mesurés les nitrates.

\begin{tabular}{|c|c|c|c|c|c|c|c|c|}
\hline Conduite & $\begin{array}{l}\text { Fertilisation } \\
\text { azotée }\end{array}$ & $\begin{array}{l}\text { Interculture } \\
\text { Colza/Blé }\end{array}$ & $\begin{array}{l}\text { Semis } \\
\text { blé }\end{array}$ & $\begin{array}{l}\text { Travail } \\
\text { du sol }\end{array}$ & $\begin{array}{c}\text { Dose azote } \\
\text { colza } \\
\text { kgN/ha }\end{array}$ & $\begin{array}{c}\text { Dose azote } \\
\text { blé } \\
\text { kgN/ha }\end{array}$ & $\begin{array}{c}\text { Rdt moy colza } \\
\text { q/ha }\end{array}$ & $\begin{array}{c}\text { Rdt moy } \\
\text { blé } \\
\text { q/ha }\end{array}$ \\
\hline N2_SN_L & Raisonnée & Sol nu & Normal & Labour & 183 & 193 & 27,8 & 97,6 \\
\hline N2_Rp_L1 & Raisonnée & Repousses & Normal & Labour & 192 & 183 & 33,4 & 96,7 \\
\hline N2_Rp_L2 & Raisonnée & Repousses & Normal & Labour & 192 & 187 & 33,1 & 96,1 \\
\hline N2_SN_S & Raisonnée & Repousses & Normal & Superficiel & 192 & 183 & 30,6 & 98,8 \\
\hline N2_RpP_L & Raisonnée & Repousses & Précoce & Labour & 216 & 177 & 33,8 & 90,3 \\
\hline N3_SN_L & Renforcée & Sol nu & Normal & Labour & 261 & 227 & 31,9 & 100,3 \\
\hline N3_Rp_L & Renforcée & Repousses & Normal & Labour & 269 & 217 & 29,4 & 95,5 \\
\hline
\end{tabular}


Tableau 3. Modalités de conduite, pratiques de fertilisation et rendements moyens obtenus de 1999-2000 à 2004-2005 à Martincourt. Ce sont les conduites des cultures précédant les cultures sous lesquelles ont été mesurés les nitrates.

\begin{tabular}{|c|c|c|c|c|c|c|c|c|}
\hline Conduite & $\begin{array}{l}\text { Fertilisation } \\
\text { azotée }\end{array}$ & $\begin{array}{c}\text { Interculture } \\
\text { Colza/Blé }\end{array}$ & $\begin{array}{l}\text { Semis } \\
\text { blé }\end{array}$ & $\begin{array}{l}\text { Travail } \\
\text { du sol }\end{array}$ & $\begin{array}{c}\text { Dose azote } \\
\text { colza } \\
\text { kgN/ha }\end{array}$ & $\begin{array}{c}\text { Dose azote } \\
\text { blé } \\
\text { kgN/ha }\end{array}$ & $\begin{array}{c}\text { Rdt moy } \\
\text { colza } \\
\text { q/ha }\end{array}$ & $\begin{array}{c}\text { Rdt moy } \\
\text { blé } \\
\text { q/ha }\end{array}$ \\
\hline N1_SN_L & Réduite & Sol nu & Normal & Labour & 126 & 113 & 17,3 & 53,6 \\
\hline N2_SN_L & Raisonnée & Sol nu & Normal & Labour & 178 & 176 & 19,5 & 53,2 \\
\hline N2_Rp_L & Raisonnée & Repousses & Normal & Labour & 178 & 176 & $n . r$. & $n . r$. \\
\hline N3_SN_L & Renforcée & Sol nu & Normal & Labour & 230 & 212 & 19,9 & 54,3 \\
\hline N3_Rp_L & Renforcée & Repousses & Normal & Labour & 230 & 212 & n.r. & n.r. \\
\hline
\end{tabular}

n.r. : non récolté, rendement non mesuré dans ce traitement.

raud par exemple le drainage démarre au plus tôt en septembre et se termine au mois d'avril au plus tard [3] ; parfois quand l'automne et I'hiver sont très secs, rien ne draine, ce fut le cas exceptionnel de l'hiver 2005-2006.

Pendant la première phase du Magneraud, le drainage a été faible à moyen : $127 \mathrm{~mm}$ en 1995-6, $194 \mathrm{~mm}$ en 1996-7 et $374 \mathrm{~mm}$ en 1997-8. Les pertes moyennes de nitrate sont de $34,4 \mathrm{~kg} \mathrm{~N} / \mathrm{ha} / \mathrm{an}$ (tableau 4). Une première approche statistique montre que cette variation du drainage s'accompagne de différences significatives de lessivage et, dans une moindre mesure, de la concentration en nitrate: $20,6 \mathrm{~kg} \mathrm{~N} / \mathrm{ha} / \mathrm{an}$ en 1995-6 37,0 en 1996-7 et $45,7 \mathrm{~kg} \mathrm{~N} / \mathrm{ha} / \mathrm{an}$ en $1997-8$.

En isolant l'effet de la succession de culture, les résultats montrent une différence très significative entre les deux successions de la rotation sur le lessivage et la concentration en nitrate. Les concentrations et le lessivage les plus forts s'observent sous le blé après le colza (succession colza-blé) avec en moyenne $54,1 \mathrm{~kg}$ $\mathrm{N} / \mathrm{ha} /$ an dans ce dispositif tandis que I'on observe seulement $14,8 \mathrm{~kg} \mathrm{~N} / \mathrm{ha} /$ an de pertes sous le colza après le blé (succession blé-colza).
Les modes de gestion de l'azote testés ici n'ont pas d'effet significatif sur les pertes de nitrate. Par rapport à la fertilisation raisonnée, la fertilisation réduite de 50 unités a fait baisser les rendements sans modifier de façon significative les pertes de nitrate. De même, la simplification du travail du sol et les changements des modalités d'apport de l'engrais n'ont pas changé les pertes de nitrate.

Au cours de la phase 2 du Magneraud, le drainage a été beaucoup plus variable avec $158 \mathrm{~mm}$ en 1998-9, $307 \mathrm{~mm}$ en 1999-2000 et $532 \mathrm{~mm}$ en 2000-1. En moyenne il a été plus élevé que durant la phase 1 (tableau 5). Les pertes moyennes atteignent ici $40,9 \mathrm{~kg}$ $\mathrm{N} / \mathrm{ha} / \mathrm{an}$. Et on observe un effet très significatif de ce drainage sur le lessivage avec $15,4 \mathrm{~kg}$ $\mathrm{N} / \mathrm{ha} /$ an en $1998-9,50,2 \mathrm{~kg} \mathrm{~N} / \mathrm{ha} /$ an en 1999 . 2000 et $57,5 \mathrm{~kg} \mathrm{~N} / \mathrm{ha} /$ an en 2000-1. L'analyse statistique de la succession ne montre pas de différence entre ce qui se passe sous le blé et sous le colza (tableau 5). Par contre, I'analyse des stratégies de gestion de l'azote montre des résultats significatifs tant du point de vue du lessivage que des concentrations. Parmi les modalités testées, deux s'avèrent particulière-

Tableau 4. Moyenne de la concentration en nitrate des eaux des bougies poreuses, du drainage mesuré dans les cases lysimétriques, et du lessivage calculé au Magneraud pour la rotation colza-blé (Total des observations $n=24$ ).

\begin{tabular}{|c|c|c|c|}
\hline $\begin{array}{l}\text { Le Magneraud } \\
\text { Phase } 1 \\
\end{array}$ & $\begin{array}{c}\text { Drainage mesuré } \\
\text { mm }\end{array}$ & $\begin{array}{l}\text { Lixiviation } \\
\mathbf{k g ~ N ~ h a ~}^{-1}\end{array}$ & $\begin{array}{c}\text { Concentration } \\
\mathrm{mm} \mathrm{NO}_{3} \mathbf{I}^{-1}\end{array}$ \\
\hline \multicolumn{4}{|l|}{ Par année } \\
\hline 1995-96 & 127 & 20,6 & 65,1 \\
\hline 1996-97 & 194 & 37.0 & 71,9 \\
\hline 1997-98 & 374 & 45,7 & 54,9 \\
\hline $\operatorname{Pr}>F$ & & 0,0074 & 0,0768 \\
\hline \multicolumn{4}{|l|}{ Par succession de cultures } \\
\hline Colza/blé & & 14,8 & 30,4 \\
\hline Blé/colza & & 54,1 & 97,5 \\
\hline $\operatorname{Pr}>F$ & & 0,0001 & 0,0001 \\
\hline \multicolumn{4}{|l|}{ Par stratégie de gestion de l'azote } \\
\hline N1_SN_LF. réduite & & 33,2 & 62,9 \\
\hline N2_SN_LF. raisonnée & & 35,5 & 64,4 \\
\hline N2_SN_S F. raisonnée + T. superficiel & & 33,4 & 60,3 \\
\hline N2'_SN_LF. standard & & 35,7 & 68,2 \\
\hline $\operatorname{Pr}>F$ & & 0,3499 & 0,2563 \\
\hline Ensemble des situations & 232 & 34,4 & \\
\hline
\end{tabular}

ment efficaces pour réduire le lessivage et les concentrations en nitrate : ce sont le raisonnement de la fertilisation par comparaison à la fertilisation renforcée (de l'ordre de $50 \mathrm{~kg}$ $\mathrm{N} / \mathrm{ha}$ ) d'une part, et la mise en place de repousses après le colza qui limitent les pertes après le colza sous le blé. Pour ne présenter que les extrêmes, le lessivage est de $61,1 \mathrm{~kg} \mathrm{~N} / \mathrm{ha} / \mathrm{an}$ pour la stratégie de fertilisation renforcée avec sol nu en interculture, tandis qu'il descend à $29,9 \mathrm{~kg} \mathrm{~N} / \mathrm{ha} / \mathrm{an}$ pour la stratégie de fertilisation raisonnée avec des repousses pour piéger les nitrates après colza.

La simplification du travail du sol et l'avancée de la date de semis du blé ne semblent pas apporter de changement significatif.

À Martincourt, le suivi a duré pendant une période de 6 ans, soient 3 rotations successives de colza-blé. Au cours de cette période, le drainage calculé dont la moyenne est de $321 \mathrm{~mm}$ a varié de 103 à $580 \mathrm{~mm}$ (tableau 6), dans une gamme proche des deux séries de mesures du Magneraud. Le lessivage moyen atteint ici $53,0 \mathrm{~kg} \mathrm{~N} / \mathrm{ha} / \mathrm{an}$. L'analyse statistique des résultats met en évidence un effet significatif non seulement de l'année, mais aussi de la succession et de la stratégie de fertilisation sur les pertes de nitrate, mais pas sur les concentrations. Suivant les années, le lessivage varie de $24,2 \mathrm{~kg} \mathrm{~N} / \mathrm{ha} /$ an en 1999 . 2000 à 95,0 kg N/ha/an en 2000-1, l'année au drainage le plus élevé. Et les concentrations les plus fortes correspondent aux années où le drainage est le plus faible : $135,8 \mathrm{mg} \mathrm{NO}_{3} / \mathrm{l}$ en 2003-4 et $124,6 \mathrm{mg} \mathrm{NO}_{3} / \mathrm{I}$ en 2004-5. Les deux successions se différencient également en termes de lessivage : $56,9 \mathrm{~kg} \mathrm{~N} / \mathrm{ha} /$ an sous le blé après le colza, et $49,2 \mathrm{~kg} \mathrm{~N} / \mathrm{ha} /$ an sous le colza après le blé. Les pertes sous colza sont ici significativement inférieures à celles sous blé, tout en étant $d$ 'un niveau relativement élevé par rapport au Magneraud. Le lessivage est de $61,4 \mathrm{~kg} \mathrm{~N} / \mathrm{ha} /$ an pour la stratégie de surfertilisation avec sol nu en interculture, alors qu'il est de $43,0 \mathrm{~kg} \mathrm{~N} / \mathrm{ha} /$ an pour la stratégie de fertilisation raisonnée avec des repousses pour piéger les nitrates après colza. La modalité avec 
Tableau 5. Moyenne de la concentration en nitrate des eaux des bougies poreuses, du drainage mesuré dans les cases lysimétriques, et du lessivage calculé au Magneraud pour la rotation colza-blé (Total des observations $n=42$ ).

\begin{tabular}{|c|c|c|c|c|}
\hline \multicolumn{2}{|l|}{$\begin{array}{l}\text { Le Magneraud } \\
\text { Phase } 2\end{array}$} & $\begin{array}{c}\text { Drainage } \\
\text { mesuré mm }\end{array}$ & $\begin{array}{l}\text { Lixiviation } \\
\text { kg N ha } \mathbf{~ h a ~}^{-1}\end{array}$ & $\begin{array}{l}\text { Concentration } \\
\mathrm{mm} \mathrm{NO}_{3} \mathrm{I}^{-1}\end{array}$ \\
\hline \multicolumn{5}{|l|}{ Par année } \\
\hline \multicolumn{2}{|l|}{ 1998-99 } & 158 & 15,4 & 42,2 \\
\hline \multicolumn{2}{|l|}{ 1999-00 } & 307 & 50,2 & 75,0 \\
\hline \multicolumn{2}{|l|}{ 2000-01 } & 532 & 57,5 & 49,8 \\
\hline \multicolumn{2}{|c|}{$\operatorname{Pr}>F$} & & $<0,0001$ & 0,0021 \\
\hline \multicolumn{5}{|c|}{ Par succession de cultures } \\
\hline \multicolumn{2}{|c|}{ Colza/blé } & & 44,5 & 52,9 \\
\hline \multicolumn{2}{|l|}{ Blé/colza } & & 37,6 & 58,4 \\
\hline \multicolumn{2}{|l|}{$\operatorname{Pr}>F$} & & 0,1011 & 0,3836 \\
\hline \multicolumn{5}{|c|}{ Par stratégie de gestion de l'azote } \\
\hline N2_SN_L & F. raisonnée & & 46,4 & 67,1 \\
\hline N2_Rp_L1 & F. raisonnée + repousses & & 29,9 & 40,0 \\
\hline N2_Rp_L2 & F. raisonnée + repousses & & 41,8 & 62,0 \\
\hline N2_RpP_L & F. raisonnée + rep. + blé précoce & & 41,2 & 51,7 \\
\hline N2_SN_S & F. raisonnée + T. simplifié & & 25,7 & 33,2 \\
\hline N3_SN_L & F. renforcée & & 61,1 & 82,1 \\
\hline N3_Rp_L & F. renforcée + repousses & & 41,3 & 53,6 \\
\hline $\operatorname{Pr}>F$ & & & 0,0090 & 0,0154 \\
\hline Ensemble des si & tuations & 332 & 40,9 & \\
\hline
\end{tabular}

Tableau 6. Moyenne de la concentration en nitrate des eaux des bougies poreuses, du drainage calculé par bilan hydrique et du lessivage calculé à Martincourt pour la rotation colza-blé (Total des observations $n=60$ ).

\begin{tabular}{|c|c|c|c|c|}
\hline \multicolumn{2}{|l|}{ Martincourt } & $\begin{array}{c}\text { Drainage calculé } \\
\text { mm }\end{array}$ & $\begin{array}{l}\text { Lixiviation } \\
\mathbf{k g ~ N ~ h a - 1}\end{array}$ & $\begin{array}{c}\text { Concentration } \\
\mathrm{mm} \mathrm{NO}_{3} \mathrm{I}^{-1}\end{array}$ \\
\hline \multicolumn{5}{|l|}{ Par année } \\
\hline 1999-00 & & 359 & 24,2 & 59,6 \\
\hline 2000-01 & & 580 & 95,0 & 71,2 \\
\hline 2001-02 & & 425 & 56,1 & 58,0 \\
\hline $2002-03$ & & 265 & 50,1 & 90,8 \\
\hline 2003-04 & & 193 & 63,0 & 135,8 \\
\hline 2004-05 & & 103 & 29,9 & 124,6 \\
\hline $\operatorname{Pr}>F$ & & & $<0,0001$ & $<0,0001$ \\
\hline \multicolumn{5}{|c|}{ Par succession de cultures } \\
\hline Colza/blé & & & 49,2 & 86,3 \\
\hline Blé/colza & & & 56,9 & 93,7 \\
\hline $\operatorname{Pr}>F$ & & & 0,0195 & 0,286 \\
\hline \multicolumn{5}{|c|}{ Par stratégie de gestion de l'azote } \\
\hline N1_SN_L & Fertilisation réduite & & 50,3 & 83,2 \\
\hline N2_SN_L & F. raisonnée & & 51,9 & 85,0 \\
\hline N2_Rp_L & F. raisonnée + repousses & & 43,0 & 73,7 \\
\hline N3_SN_L & F. renforcée & & 61,4 & 104,2 \\
\hline N3_Rp_L & F. renforcée + repousses & & 58,7 & 103,9 \\
\hline $\operatorname{Pr}>F$ & & & 0,0064 & 0,165 \\
\hline Ensemble des & tuations & 321 & 53,0 & \\
\hline
\end{tabular}

sous-fertilisation ne se distingue pas de la modalité avec fertilisation raisonnée.

\section{Discussions sur les pertes comparées dans les expérimentations}

Au-delà de cette analyse statistique, passons à une approche plus systémique pour caractéri- (tableaux 4 et 5). La contribution de la succession colza-blé est plus importante que celle de la succession blé-colza (figures 1 à 4), en dépit de l'interaction avec le drainage de l'année climatique.

En situation de fertilisation réduite pour les deux cultures, une stratégie testée en première phase, la différence n'est pas significative avec la situation de référence.

La situation de fertilisation renforcée, une stratégie testée en phase 2, conduit à des pertes de $61,1 \mathrm{~kg} \mathrm{~N} / \mathrm{ha} / \mathrm{an}$, sans que cette différence soit significative avec le traitement de référence.

En situation de fertilisation renforcée et d'utilisation de repousses, les pertes passent à $41,3 \mathrm{~kg} \mathrm{~N} / \mathrm{ha} / \mathrm{an}$ sans différence significative avec la fertilisation renforcée en sol nu. L'usage des repousses en fertilisation raisonnée conduit à des pertes de 29,9 et $25,7 \mathrm{~kg} \mathrm{~N} / \mathrm{ha} / \mathrm{an}$, des valeurs significativement différentes de celles du traitement fertilisation renforcée sans repousses.

Pour Martincourt, les pertes de la situation de référence sont de $51,9 \mathrm{~kg} \mathrm{~N} / \mathrm{ha} / \mathrm{an}$ (figures 5 et 6). La fertilisation réduite, qui se situe à un niveau de pertes de $50,3 \mathrm{~kg} \mathrm{~N} / \mathrm{ha} / \mathrm{an}$, ne s'en distingue pas de façon significative. Comme au Magneraud, seuls se distinguent les traitements fertilisation renforcée sans repousses $(61,4 \mathrm{~kg} \mathrm{~N} / \mathrm{ha} / \mathrm{an})$ et fertilisation raisonnée avec repousses (43,0 kg N/ha/an) dont l'écart est significatif.

Quelle interprétation peut-on faire de cette comparaison des deux sites, I'un en climat plutôt continental, l'autre en climat plus océanique? Dans les deux sites, le drainage, qui a été estimé de deux manières différentes, serait assez similaire si l'on se fie à la comparaison des valeurs des deux années communes. Les stratégies de gestion de l'azote semblent également avoir des effets similaires avec un poids déterminant de l'équilibre de fertilisation (sans effet améliorant de la sous-fertilisation) d'une part, et de la couverture du sol durant l'interculture courte colza-blé d'autre part : le système avec fertilisation raisonnée et repousses est le plus performant, le système sans repousses avec fertilisation renforcée est le moins performant avec des pertes de plus de $60 \mathrm{~kg} \mathrm{~N} / \mathrm{ha} / \mathrm{an}$. Dans la rotation colza-blé, lorsque le sol est nu durant I'interculture colza-blé, les pertes de nitrate les plus importantes de la rotation ont lieu sous le blé qui suit le colza: $14,8 \mathrm{~kg}$ $\mathrm{N} / \mathrm{ha} /$ an sous le colza, et $54,1 \mathrm{~kg} \mathrm{~N} / \mathrm{ha} /$ an sous le blé, soit un écart de plus de $40 \mathrm{~kg} \mathrm{~N} / \mathrm{ha} / \mathrm{an}$. Cet écart des moyennes est plus faible dans les deux autres dispositifs (tableaux 5 et 6), car dans ces dispositifs plus récents où les traitements avec repousses de colza sont nombreux, celles-ci absorbent de l'azote après le colza, limitent les pertes de nitrate sous le blé qui suit, en réduisant ainsi l'écart entre les pertes sous 


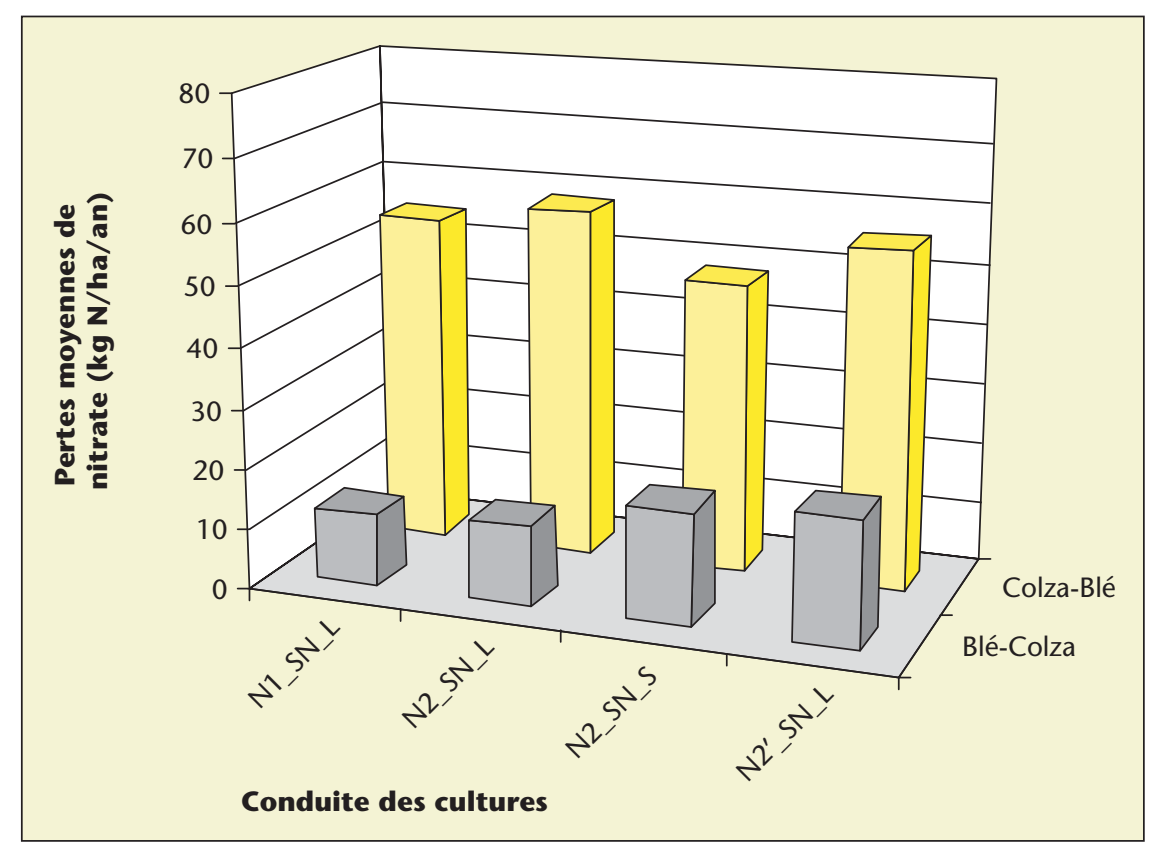

Figure 1. Pertes de nitrate moyennes de chaque succession au sein de chaque conduite de cultures au Magneraud (phase 1 : 1995-6 à 1997-8).

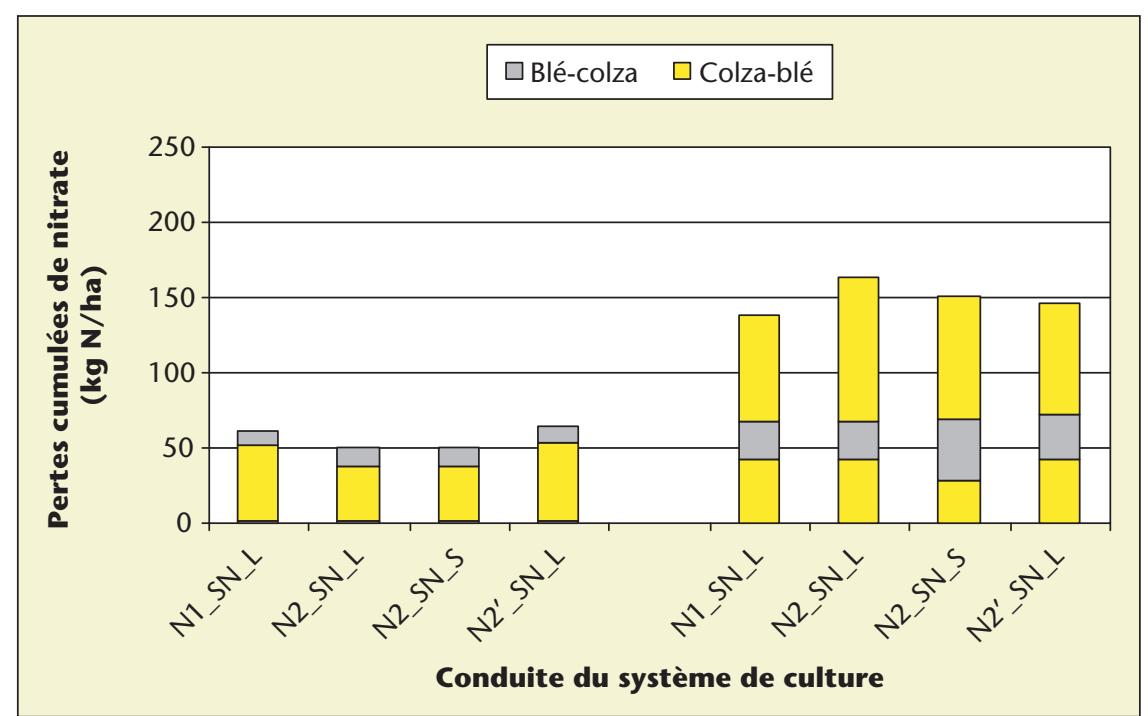

Figure 2. Pertes de nitrate cumulées sur 3 années de chaque conduite de cultures au Magneraud (phase 1 : 1995-6 à 1997-8).

blé et les pertes sous colza. En effet, ce qui caractérise la rotation colza-blé avec des sols nus à chaque interculture, ce sont des pertes d'importance très différente suivant la succession comme le montre la figure 1. Après le blé, on constate qu'il y a relativement peu d'azote minéral dans le sol du fait que les reliquats d'azote minéral dans le sol à la récolte sont relativement faibles mais aussi parce que les pailles de blé qui sont enfouies sont pauvres en azote et qu'elles réorganisent beaucoup d'azote après leur enfouissement. De plus, présent dans le sol en fin d'été. Enfin, l'absorption d'azote par le blé au cours de l'automne est relativement limitée parce qu'il est semé plus d'un mois après le colza, et que sa vitesse de croissance et d'absorption d'azote est plus faible. Au cours de cette rotation, c'est la coïncidence entre la faible absorption par le blé à l'automne et la forte disponibilité en azote minéral après le colza qui conduit à des pertes pouvant être élevées à cette phase, et la coïncidence entre la forte absorption d'azote par le colza levé tôt et la faible quantité d'azote minéral dans le sol après le blé qui conduit à des pertes pouvant être très faibles. Dans ces conditions, que l'on a rencontrées au Magneraud dans la première phase de l'expérimentation, les pertes de la rotation sont réparties de façon très déséquilibrée entre les deux phases de la succession. Toute intervention permettant de réduire les pertes de nitrate sous le blé qui suit le colza est essentielle dans I'amélioration de ces performances environnementales. $\mathrm{Par}$ contre, compte tenu de la faiblesse des pertes sous le colza après le blé, il y a peu à attendre au final d'une optimisation de la fertilisation azotée du blé sur les pertes sous le colza qui suit dans la mesure où celles-ci sont très faibles. Les résultats expérimentaux le confirment notamment avec l'effet des repousses de colza qui permettent de réduire la quantité d'azote minéral dans le sol dans le sol après le colza au cours de l'été, mais aussi par l'effet de la mâ̂trise de la fertilisation qui est essentielle à réaliser pour la culture de colza.

Lorsque cette rotation est conduite avec ces techniques, comme cela a été testé lors de la deuxième phase du Magneraud, cela a abouti à des pertes moyennes à la rotation de $29,9 \mathrm{~kg}$ $\mathrm{N} /$ ha/an grâce à une forte réduction des pertes sous le blé qui sont fortement réduites, sans que les pertes sous colza soient fortement affectées (figure 3).

Une caractéristique important du site de Martincourt réside dans le niveau élevé de pertes de nitrate notamment sous le colza. Rappelons que les rendements obtenus y sont faibles, alors que la fertilisation était prévue pour des rendements objectifs deux fois plus élevés. $A$ posteriori, nous pouvons ainsi considérer que nous sommes de fait partout dans des situations de fertilisation renforcée compte tenu des faibles rendements réalisés, capables d'accrô̂tre l'azote minéral présent dans le sol à la récolte de chacune des cultures. Enfin, le colza a régulièrement rencontré des difficultés d'implantation de telle sorte que, dans les faits, sa croissance a été anormalement faible quelles que soient les conditions climatiques automnales. Ainsi, une condition nécessaire à l'obtention de faibles pertes sous le colza semble être la réussite d'une levée assez précoce du colza. Les pertes relativement élevées du Magneraud 


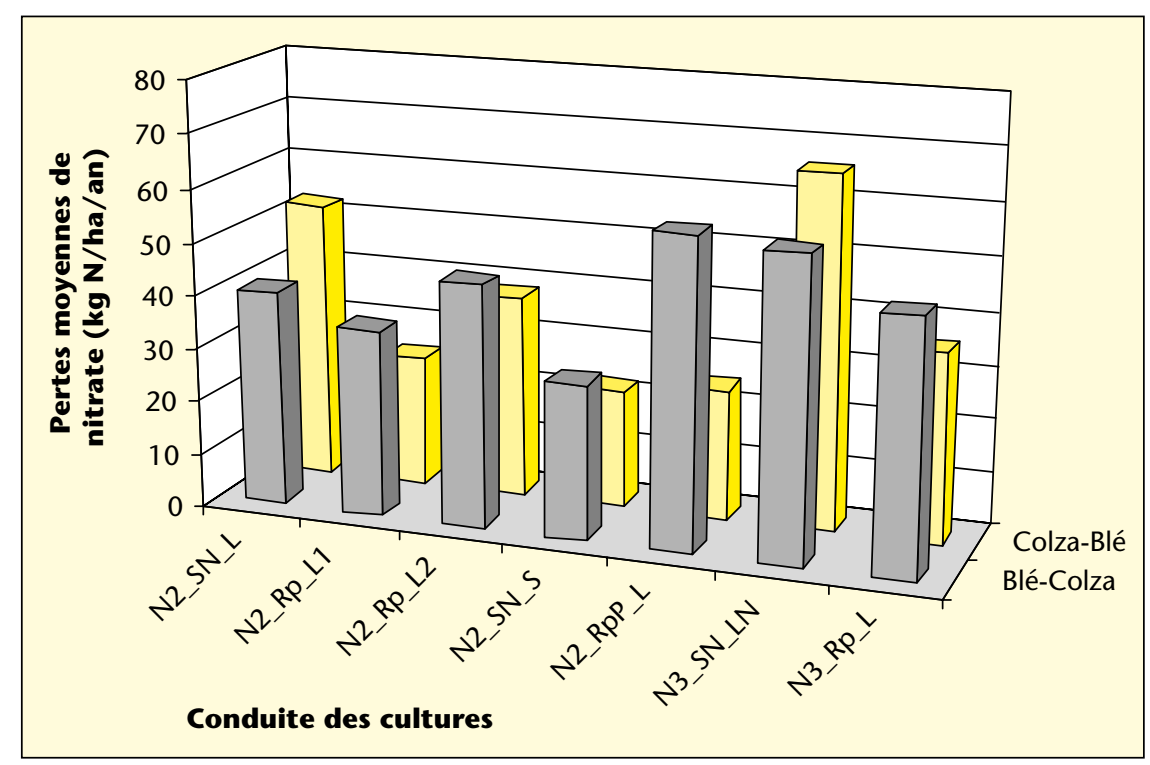

Figure 3. Pertes de nitrate moyennes de chaque succession au sein de chaque conduite de cultures au Magneraud (phase 2: 1998-9 à 2000-1).

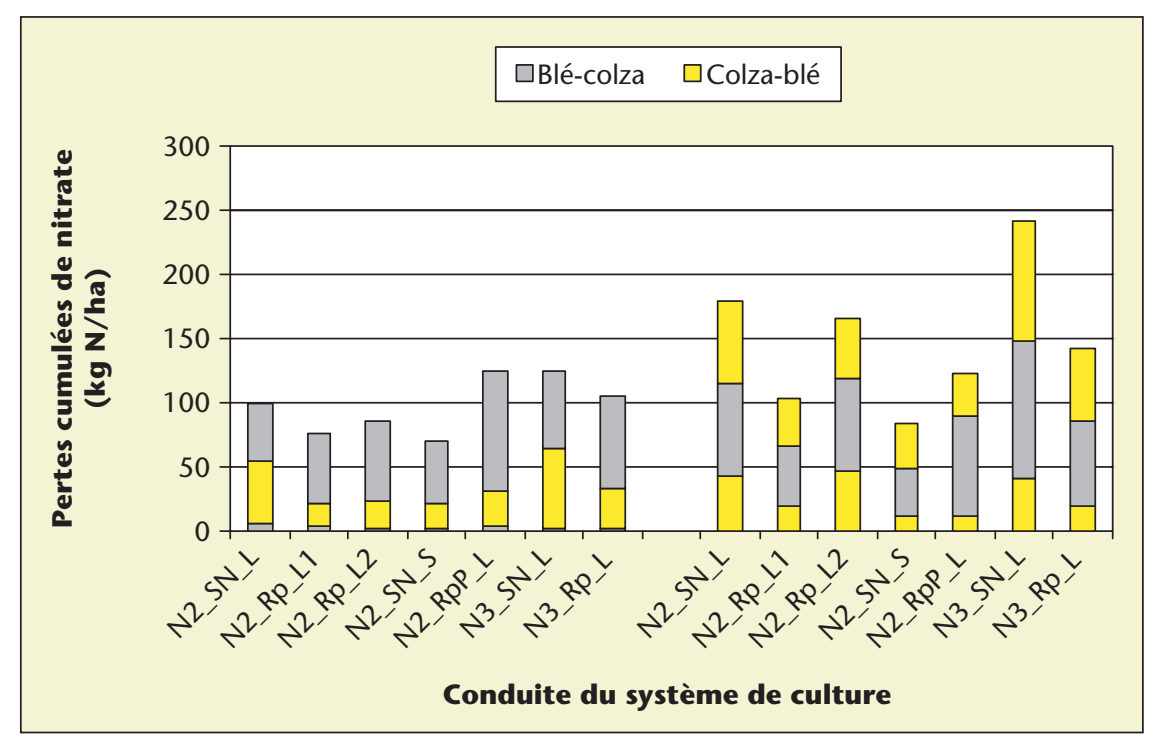

Figure 4. Pertes de nitrate cumulées sur 3 années de chaque conduite de cultures au Magneraud (phase 2 : 1998-9 à 2000-1).

pendant la phase $2 \mathrm{~s}^{\prime}$ expliquent en partie pour les mêmes raisons: des rendements en colza assez moyens: $30 \mathrm{q} /$ ha environ (tableau 2), sans rapport avec les objectifs de rendements de $40 \mathrm{~g} /$ ha environ, utilisés pour le calcul de fertilisation, calés sur les rendements de la phase 1 (tableau 1). Mais la lame drainante relativement élevée des 3 années correspondantes à la phase 2 contribue également à ces pertes élevées. Ainsi l'adéquation entre les rendements réalisés et les objectifs pris pour le raisonnement de la fertilisation du colza est une condition nécessaire à la réduction des pertes d'azote sous le blé après le colza.
Cette approche expérimentale sous une rotation colza-blé montre comment varient les pertes de nitrate au champ, dans 2 types de sol de deux stations expérimentales, pour 6 années de mesures et quelques modalités de gestion de l'azote. Afin d'extrapoler ces résultats à de nouvelles situations, nous allons utiliser des résultats issus de modèles pour explorer $d^{\prime}$ autres conditions climatiques et d'autres sols où l'on ne dispose pas de mesures expérimentales. Pour que ces modèles soient performants, les résultats ci-dessus montrent qu'ils doivent être sensibles au type de sol, à l'excé- dent hydrique, comme à la fertilisation renforcée et l'absorption d'azote par les cultures (colza, repousses) pendant l'automne.

\section{Le diagnostic des pertes par simulation avec des modèles}

Les pertes de nitrate sous les rotations colzacéréales ont également été étudiées par d'autres auteurs dans le cadre d'une approche mixte intégrant des mesures d'azote minéral dans le sol couplées avec un modèle de l'évolution de l'azote dans le sol aboutissant à un calcul des nitrates lixiviés. N. Beaudoin [4] présente les résultats obtenus dans les parcelles du bassin de Bruyères (Aisne) en utilisant le modèle LIXIM [5] à partir de mesures d'azote minéral réalisées après la récolte. Les résultats portent sur 9 années, 4 sols et 6 successions différentes. Les pertes moyennes sont évaluées à $17 \mathrm{~kg} \mathrm{~N} /$ ha pour la succession blé-colza, et à $32 \mathrm{~kg} \mathrm{~N} /$ ha pour la succession colza-blé, sans que cette différence soit significative. Le niveau relativement faible des pertes tient à l'importance des sols limoneux profonds dans le bassin, et à une lame d'eau drainante relativement faible. La tendance observée entre les deux successions est cohérente avec les différences qui ont été observées à Martincourt et au Magneraud (phase 1).

Les résultats expérimentaux obtenus au Magneraud et à Martincourt ont permis d'améliorer la compréhension des mécanismes de pertes de nitrate dans les 2 types de milieux étudiés et sous les climats rencontrés au cours des 10 années d'études. L'étude réalisée ici sur le bassin de Bruyères permet de confirmer le comportement des successions colza-blé et blé-colza sous un autre climat. Comment extrapoler ces connaissances à d'autres types de sol et de climat? Les modèles intégrant l'absorption d'azote par les cultures et la dynamique de l'azote dans le sol semblent les outils les mieux adaptés à cet exercice. Nous avons choisi de travailler avec le modèle DEAC [6], qui est issu d'une collaboration entre Arvalis, I'ITB et le Cetiom, trois instituts techniques agricoles français. II est conçu spécifiquement pour calculer 2 variables (la quantité d'azote lessivé pendant la période de drainage automnal et hivernal et la concentration en nitrate de l'eau drainée) à partir de données simples concernant le sol, le climat, le système de culture et les rendements. La campagne est divisée en trois périodes : de la sortie de l'hiver à la récolte de la culture, de la récolte au début du drainage et la période de drainage, elle-même divisée en 2 phases: du début du drainage à la sortie de I'hiver et de la sortie de l'hiver à la fin du drainage. Le modèle estime la quantité d'azote minéral dans le sol à quatre moments clés : à la récolte, au début du drainage, à la sortie de 


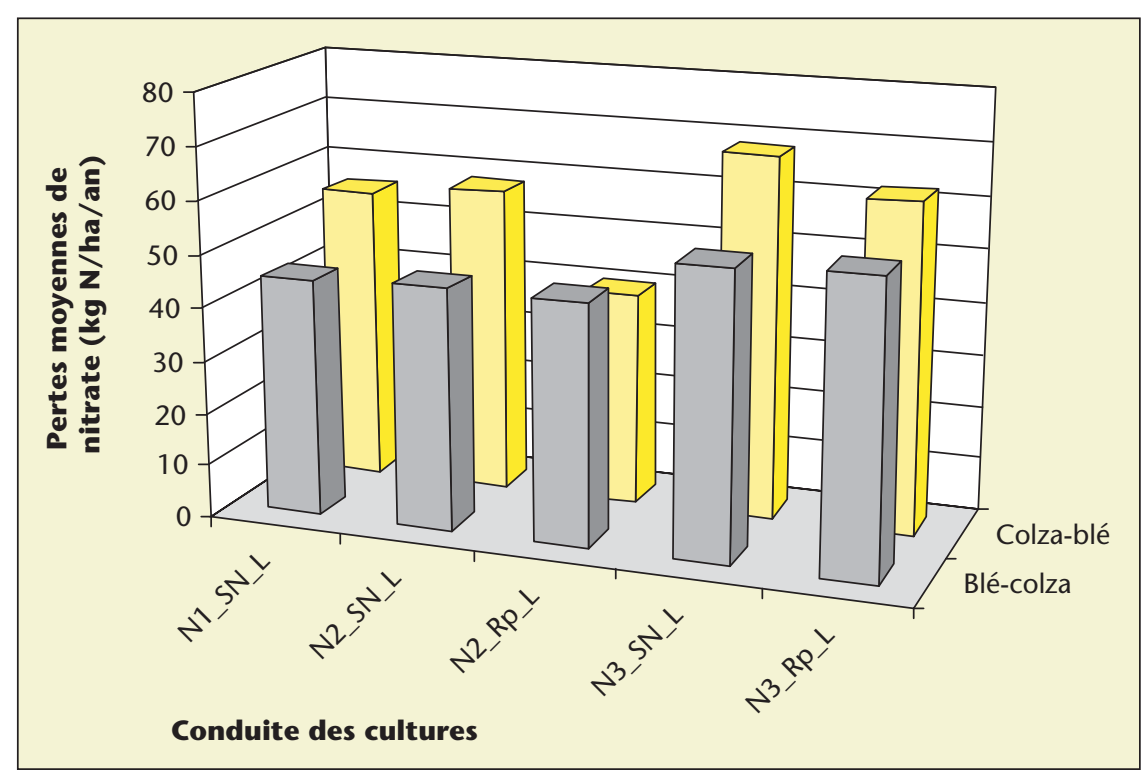

Figure 5. Pertes de nitrate moyennes de chaque succession au sein de chaque conduite de cultures à Martincourt (1999-2000 à 2004-2005).

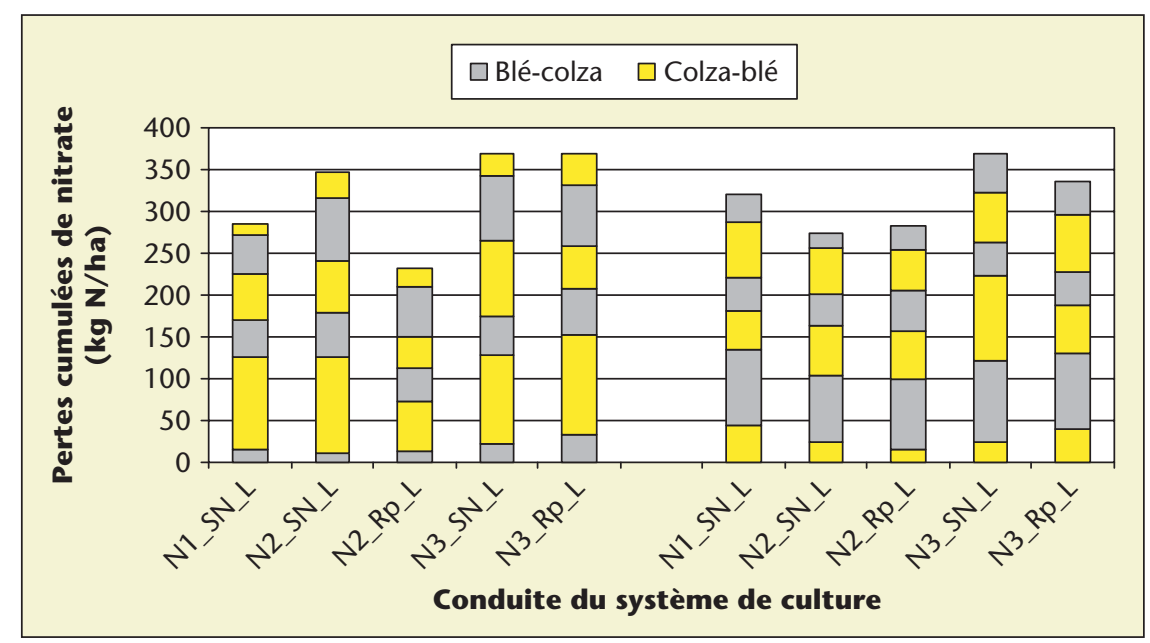

Figure 6. Pertes de nitrate cumulées sur 6 années de chaque conduite de cultures à Martincourt (1999-2000 à 2004-2005).

I'hiver et à la fin du drainage. À partir de ces valeurs, la quantité d'azote lessivé puis la concentration en nitrate sont simulées.

À partir de la base de données du Magneraud, E. Berthelin [7] a montré que ce modèle présentait une bonne aptitude à simuler le drainage comme les effets des différents modes de gestion de l'azote sur le lessivage des nitrates (fertilisation renforcée, cultures pièges à nitrate comme les repousses). Par contre, il présente des limites dans la simulation des effets des successions de la rotation colza-blé, en sousestimant les pertes sous les colzas (notamment en cas de drainage précoce) et en surestimant les pertes après le colza (par surestimation de
- sol profond avec un enracinement de $100 \mathrm{~cm}$, et une réserve utile RU de $129 \mathrm{~mm}$, permettant un rendement moyen de $32 \mathrm{q} / \mathrm{ha}$ de colza et $80 \mathrm{q} /$ ha de blé,

- sol superficiel avec un enracinement de $50 \mathrm{~cm}$, et une réserve utile RU de $71 \mathrm{~mm}$, limitant le rendement moyen à $28 \mathrm{q} / \mathrm{ha}$ de colza et $70 \mathrm{q} / \mathrm{ha}$ de blé.

- 2 niveaux de fertilisation: fertilisation optimale (ou raisonnée) et surfertilisation (ou fertilisation renforcée) d'environ $70 \mathrm{kgN} / \mathrm{ha}$ en colza et $50 \mathrm{kgN} / \mathrm{ha}$ en blé.

- 2 types de gestion de l'interculture : sol nu entre blé et colza et entre colza et blé ; repousses après colza et avant blé.

Les dates de semis et de récolte ont été adaptées aux pratiques régionales actuelles.

\section{Résultats}

Sous le climat du Magneraud, en sol profond, avec le système de culture colza-blé avec fertilisation raisonnée et sol nu après colza, les pertes médianes ont été estimées à environ $60 \mathrm{~kg} \mathrm{~N} / \mathrm{ha} / \mathrm{an}$ sous blé et $10 \mathrm{~kg} \mathrm{~N} / \mathrm{ha} / \mathrm{an}$ sous colza, ce qui correspond assez bien à ce qui a été observé pendant la première phase expérimentale (tableau 4). Les simulations indiquent comment s'accroissent les pertes avec la fertilisation renforcée (surfertilisation) en passant de 60 à $100 \mathrm{~kg} \mathrm{~N} / \mathrm{ha} /$ an en médiane sous le blé (figure 7) et de 10 à $30 \mathrm{~kg} \mathrm{~N} / \mathrm{ha} /$ an sous le colza (figure 8). Après le colza, les résultats de l'effet des repousses sont notables avec des pertes médianes de l'ordre de $20 \mathrm{~kg} \mathrm{~N} / \mathrm{ha} / \mathrm{an}$ en fertilisation raisonnée comme en fertilisation renforcée.

En sol superficiel, les pertes s'accroissent systématiquement sous le blé après sol nu. La présence d'une culture comme le colza ou ses repousses en fin d'été réduit cette augmentation de pertes due au sol plus superficiel. Dans ces simulations avec le climat du PoitouCharentes, les pertes médianes sous cette rotation colza-blé varient assez fortement suivant les situations. À une extrémité, on trouve les parcelles surfertilisées des rendzines superficielles avec sol nu en été où ces pertes atteignent $70 \mathrm{~kg} \mathrm{~N} / \mathrm{ha} / \mathrm{an}$ (moins de 110 sous blé et plus de 30 sous colza); à l'autre, les parcelles à fertilisation raisonnée des rendzines profondes avec repousses après colza où ces pertes se limitent à $15 \mathrm{~kg} \mathrm{~N} / \mathrm{ha} / \mathrm{an}$ ( 20 sous blé et 10 sous colza).

À Bourges (C), les tendances sont les mêmes. Si les pertes sous colza sont toujours plus faibles que sous blé, l'écart est moindre entre les deux successions de la rotation est moindre qu'au Magneraud. Les pertes extrêmes de la rotation selon les sols et la stratégie de gestion de l'azote varient en médiane de 70 à $15 \mathrm{~kg} \mathrm{~N} / \mathrm{ha} / \mathrm{an}$, également. 


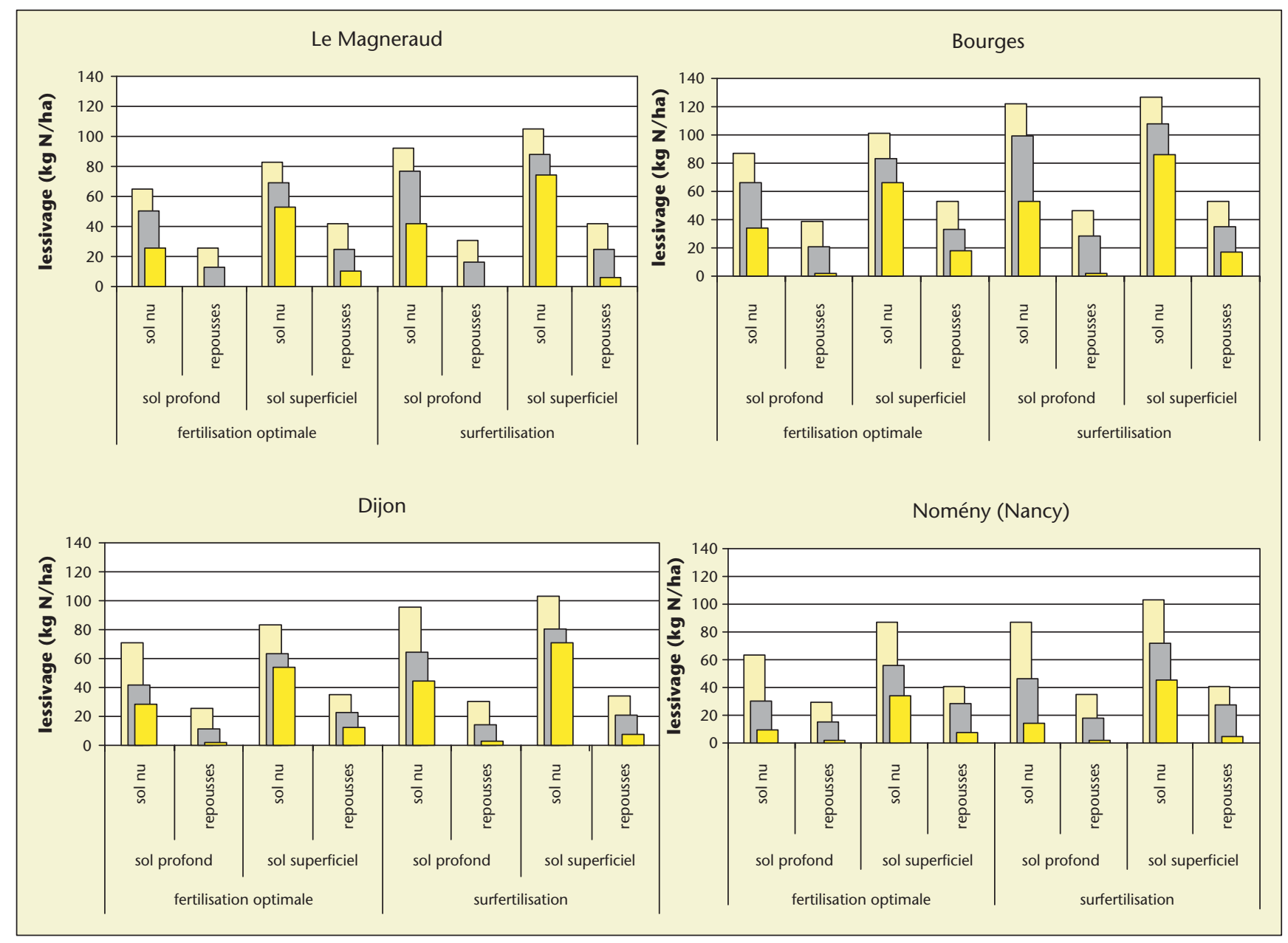

Figure 7. Pertes de nitrate simulées de la succession colza-blé dans 4 stations climatiques (médiane, décile 1 et 9).

À Dijon, les pertes sous blé sont proches des précédentes, par contre les pertes sous colza sont encore plus fortes. Les pertes médianes extrêmes de la rotation s'élèvent entre 70 et $20 \mathrm{~kg} \mathrm{~N} / \mathrm{ha} / \mathrm{an}$.

À Nomény $(\mathrm{L})$, les pertes du neuvième décile sont proches des deux stations précédentes, mais le premier décile est plus bas : on y rencontre plus souvent de faibles niveaux de pertes comme au Magneraud sous colza, et les plus faibles de l'ensemble sous le blé. Et au final les pertes médianes extrêmes se limitent à la fourchette 60 et $15 \mathrm{~kg} \mathrm{~N} / \mathrm{ha} / \mathrm{an}$.

Ces simulations mettent en évidence une certaine variabilité des pertes de nitrate suivant le poste climatique. Cependant, la variabilité entre postes est souvent inférieure à la variabilité interannuelle de chacun. Sous le climat de la France métropolitaine et sur les rendzines ayant des réserves utiles comprises entre 70 et $130 \mathrm{~mm}$ de réserve, selon ces simulations, la rotation engendre des pertes médianes de 15 à $70 \mathrm{~kg} \mathrm{~N} / \mathrm{ha} /$ an suivant le sol et la stratégie de gestion de l'azote adoptée. Les pertes dans les

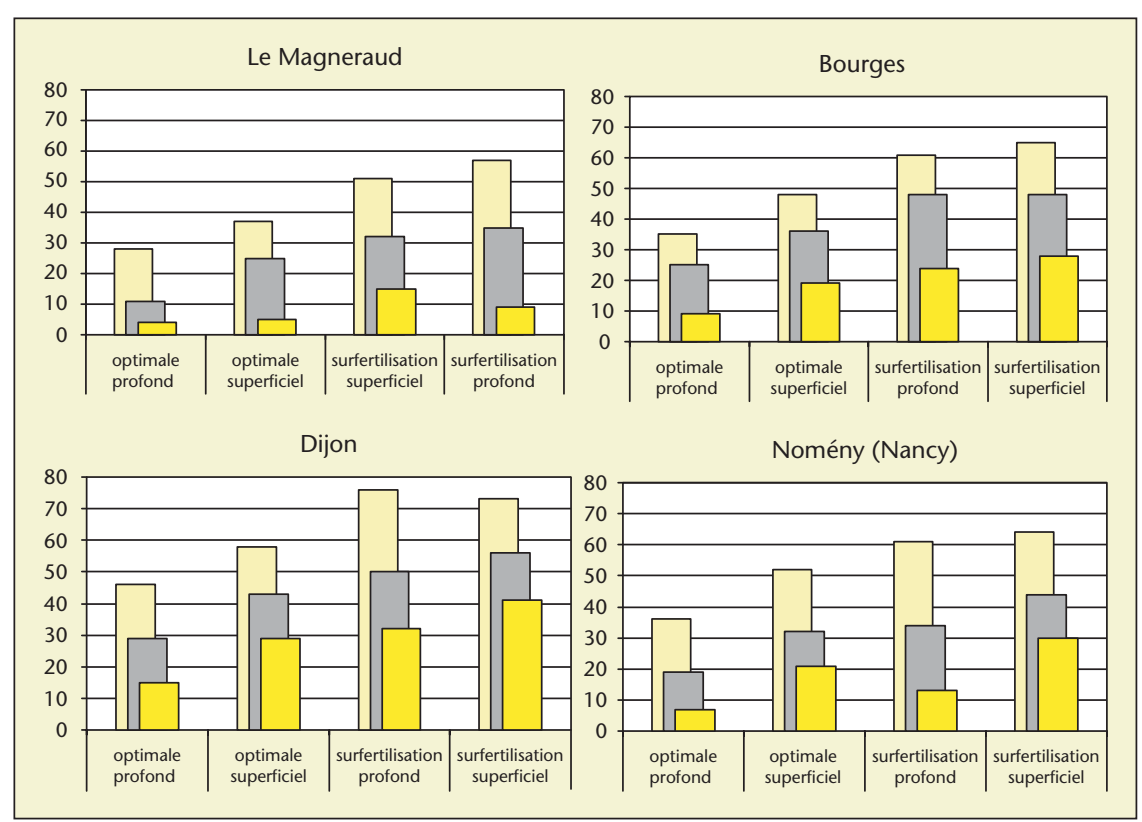

Figure 8. Pertes de nitrate simulées de la succession blé-colza dans 4 stations climatiques (médiane, décile 1 et 9). 
sols les plus profonds sont plus faibles que dans les sols plus superficiels. Sous le blé après le colza, les différences entres les stratégies de gestion de l'azote sont fortes: 40 à $80 \mathrm{~kg}$ $\mathrm{N} / \mathrm{ha} / \mathrm{an}$ d'écart entre les extrêmes suivant la situation; pendant cette phase de la rotation colza-blé, la maîtrise de la gestion de l'azote permet fortement les pertes d'azote. En effet, sous le colza après le blé, l'écart entre les stratégies extrêmes ne va pas au-delà d'une vingtaine de $\mathrm{kg} \mathrm{N} / \mathrm{ha} / \mathrm{an}$.

Une fertilisation réduite, au-dessous de l'optimum, ne conduit pas une réduction des pertes de nitrate dans cette rotation.

Une fertilisation renforcée de 50 à $70 \mathrm{~kg} \mathrm{~N} / \mathrm{ha}$ se traduit par un accroissement de pertes : les pertes médianes simulées s'accroissent ainsi de 15 à 30 unités suivant le sol et la région.

La mise en place de repousses de colza permet de réduire les pertes sous le blé qui suit: les pertes médianes simulées sont réduites pour atteindre des valeurs toujours inférieures ou égales à $40 \mathrm{~kg} \mathrm{~N} / \mathrm{ha} / \mathrm{an}$, soit au même niveau que les pertes sous colza, voire même inférieures dans les 3 autres régions.

\section{Discussion : des résultats de pertes de nitrate convergents}

Les trois approches par expérimentation et/ou modélisation réalisées en France métropolitaine pour estimer les pertes de nitrate dans les rotations colza céréales aboutissent à des résultats convergents. Dans la mesure où i) la levée et l'implantation du colza sont réussies, ii) les fertilisations azotées sont raisonnées et iii) les rendements réalisés proches des objectifs, en sol superficiel et laissé nu en interculture, les pertes sous colza sont souvent moitié moins élevées que sous blé ; ces pertes, et le plus souvent cet écart, se réduisent en sol profond. Ces résultats sont conformes avec les résultats expérimentaux de K. Sieling [8] menés depuis 1991 à l'université de Kiel en Allemagne. Dans un sol limoneux (luvisol) et avec un drainage ayant varié entre 0 et $490 \mathrm{~mm}$, la rotation triennale colza-blé-orge a été conduite pendant 9 années consécutives avec une grande gamme de fertilisation azotée, mais sans repousses. Avec des niveaux de fertilisations correspondant à la gamme étudiée ci-dessus, les pertes moyennes sur 9 ans atteignent 26 et $33 \mathrm{~kg} \mathrm{~N} / \mathrm{ha} /$ an sous le colza après l'orge, 42 et $55 \mathrm{~kg} \mathrm{~N} / \mathrm{ha} /$ an sous le blé après le colza, et 30 et $44 \mathrm{~kg} \mathrm{~N} / \mathrm{ha} /$ an sous l'orge après le blé. La hiérarchie relative est identique : pertes relativement faibles sous le colza, pertes relativement importantes après le colza sous le blé, et on voit ici la succession blé-orge se positionner au niveau intermédiaire.
Devant la différence entre les deux successions de culture de la rotation biennale, beaucoup d'auteurs ont considéré que la cause des pertes importantes après le colza résidait simplement dans le fait que le bilan azoté du colza calculé par la différence entre les apports d'azote sous forme d'engrais et les exportations d'azote via la récolte des graines est relativement élevé. Reau et al. $[9,10]$ donnent par exemple une valeur de ce bilan azoté de 52 pour le colza et de 19 pour le blé (chacun fertilisé avec $182 \mathrm{~kg}$ $\mathrm{N} / \mathrm{ha}$ ), en soulignant que cette approche par le bilan azoté confond les différentes formes de I'azote dans une parcelle notamment les formes organiques et les formes minérales, de même qu'il ne prend pas en compte l'azote absorbé par les cultures tant que cet azote n'a pas été exporté avec la récolte. Sieling [8] a démontré dans le dispositif ci-dessus que s'il existe une corrélation entre le bilan azoté et les pertes de nitrate d'une succession donnée, cette relation est très variable $d^{\prime} u n e$ succession de cultures à l'autre: dans son dispositif, en moyenne, $25 \%$ du surplus du bilan azoté du blé précédant une orge est lessivé, tandis que seulement $13 \%$ de ce surplus est lessivé dans le cas d'un colza précédant un blé. La dualité de cette relation fait que le bilan azoté ne peut pas être utilisé pour comparer les pertes de nitrate après deux cultures différentes et qu'il vaut mieux l'utiliser soit pour comparer plusieurs stratégies de gestion de l'azote pour une même culture, soit pour identifier les excédents structurels d'azote dans les exploitations d'élevage.

Les cultures d'hiver ont la caractéristique de lever en été ou en automne et de commencer à absorber de l'azote avant la fin du drainage et parfois même avant le début du drainage. De même, les cultures intermédiaires et les repousses de colza sont capables d'organiser de l'azote minéral avant que celui-ci ne soit lessivé. Cultures d'hiver et cultures intermédiaires sont ainsi capables de réduire le lessivage, grâce à leur absorption automnale, indépendamment du fait qu'une partie de cet azote est ensuite exportée par la récolte (culture de production) ou pas (culture intermédiaire).

La limite du bilan azoté est qu'il ne caractérise que l'effet précédent via l'estimation de l'azote total que laisse la culture dans la parcelle compte tenu de ce qu'elle a reçu, et du cumul de ce qu'elle a absorbé ou de ce qu'elle a exporté à la récolte. Ce bilan azoté ne prend pas en compte l'effet suivant des cultures $\mathrm{d}^{\prime}$ 'hiver et des cultures intermédiaires en termes d'absorption de l'azote minéral présent dans le sol avant que celui-ci ne soit entraîné en profondeur sous l'effet du lessivage. Or cette organisation temporaire de l'azote minéral par ces cultures est un des déterminants des pertes dans ces rotations de culture d'hiver. Ainsi les fortes pertes après le colza ne peuvent pas se résumer au fait que le bilan azoté du colza est moins favorable, cela tient autant au fait que cette plus forte disponibilité en azote après le colza coïncide avec une culture suivante le blé qui n'a que de faibles capacités à absorber de l'azote. De même, le fait que le bilan azoté du blé soit plus favorable n'est pas l'élément le plus déterminant des faibles pertes après le blé ; en effet, ces faibles pertes sont avant tout dues à l'effet suivant du colza capable d'absorber beaucoup d'azote à l'automne et jouer un rôle de piège à nitrate.

Pour comprendre les pertes de nitrate au cours d'une rotation, il semble ainsi essentiel de caractériser chacune des successions de culture en estimant les risques par combinaison entre l'effet « précédent » de la culture principale et l'effet « suivant » de la culture qui lui succède. Si la culture précédente peut être caractérisée par son bilan azoté, la culture suivante (culture de production ou culture intermédiaire non récoltée) doit être caractérisée par sa capacité d'absorption d'azote avant le début du drainage et au cours de la phase de drainage.

Et dans cette rotation, la clé d'un système de culture conduisant à de faibles pertes de nitrate réside dans la capacité à piéger de l'azote minéral en fin d'été, en régularisant la réussite de l'implantation du colza pour limiter les pertes sous le colza, mais aussi en favorisant les repousses pour absorber l'azote minéral présent après le colza compte tenu de la faible capacité d'absorption du blé. Ces repousses sont déterminantes dans les situations où le bilan azoté du colza est particulièrement défavorable soit à cause d'une fertilisation non maîtrisée soit à cause d'un accident de culture ayant fortement pénalisé l'absorption finale $d^{\prime}$ azote et le rendement du colza : en effet, ces repousses sont capables de piéger l'essentiel du l'azote minéral supplémentaire issu d'une fertilisation renforcée. Ainsi, dans la mesure où le colza et ses repousses sont capables de piéger les nitrates chaque année dans une rotation biennale colza-blé, le raisonnement de la fertilisation pourrait devenir secondaire (dans la seule perspective de limiter de lessivage des nitrates). Par contre, en l'absence de l'utilisation de repousses, la maîtrise de la fertilisation azotée du colza est nécessaire sans quoi les pertes de nitrate peuvent être très importantes, elle reste cependant secondaire pour le blé tant que I'on réussit régulièrement l'implantation précoce du colza, qui est alors en mesure de piéger le nitrate supplémentaire issu d'une fertilisation renforcée par exemple. Enfin, pour les rotations plus longues comme la rotation triennale colza-blé-orge d'hiver, en l'absence de culture piège à nitrate après le blé, la maîtrise de la fertilisation azotée du blé ne peut plus être considérée comme secondaire, et devient la clé de la maîtrise des pertes de nitrate pendant la 
succession blé-orge, car l'orge n'a pas les mêmes capacités de piégeage que le colza.

Les simulations avec le modèle DEAC indiquent que les pertes de nitrate ne varient pas énormément entre les stations climatiques des régions françaises productrices de colza. Dans ces conditions quelle peut être I'utilisation des modèles?

II y a une forte variabilité du drainage d'une année à l'autre, le modèle est indispensable pour relativiser les résultats expérimentaux obtenus au-delà des quelques années que dure l'expérimentation compte tenu de son coût. II est également important pour extrapoler les résultats expérimentaux aux autres types de sol d'une région. II peut contribuer à identifier les systèmes de culture à promouvoir dans le cadre de la mise au point de bonnes pratiques agricoles, comme à identifier les véritables enjeux environnementaux du développement des différentes méthodes de fertilisation du raisonnement. II peut également permettre de cerner comment varie l'importance de la fertilisation du raisonnement d'une culture suivant la place qu'elle occupe dans la rotation et notamment selon la culture qu'elle précède. Enfin, un modèle s'avère assez indispensable pour objectiver la construction des grilles de risques de pertes de nitrate à l'échelle d'un bassin, dans l'objectif de faciliter le diagnostic et l'évaluation des opérations de conseils par la mise au point de références opérationnelles pour l'action. Cela a déjà été réalisé dans le cadre d'une opération Ferti-mieux avec l'outil DEAC [11]. Afin de d'aller au-delà des limites de cet outil, notamment à cause de son pas de temps de simulation assez long, les instituts techniques agricoles et I'Inra ont maintenant entrepris d'étudier un outil opérationnel plus performant. Afin de mieux diagnostiquer et évaluer l'ensemble des pertes d'azote, cet outil vise à rendre compte des pertes d'azote sous ses principales formes (nitrate mais aussi ammoniac et protoxyde d'azote) en relation avec le bilan azoté de la rotation et l'évolution de l'azote organique du sol, dans le cadre du projet Azosystem.

Remerciements. Les auteurs remercient les équipes des stations expérimentales du Magneraud de Arvalis et du Cetiom, et l'équipe de la station expérimentale du Cetiom à Nancy qui ont réalisé les essais, ainsi que Dominique Wagner, Christine Gigandon, Sophie Vallade pour leur contribution à la synthèse des données, sans oublier Edouard Berthelin pour la réalisation du test des modèles.

Financements. Les expérimentations du Magneraud et de Martincourt ont bénéficié des financements de l'agence Agrice animée par l'Ademe, et de l'Onidol.

\section{RÉFÉRENCES}

1. CHAMPOLIVIER L, REAU R, WAGNER D, ESTRAGNAT A. Connaître et maîtriser les pertes d'azote dans les rotations avec oléagineux. Oléoscope 2004 ; 76 : 14-8.

2. MEYNARD JM, REAU R, ROBERT D, SAULAS P. In : Evaluation expérimentale des itinéraires techniques. In: Expérimenter sur les conduites de culture : un nouveau savoir-faire au service d'une agriculture en mutation. Paris: Ministère de I'agriculture DERF et ACTA, 1996 : 63-72.
3. BOUTHIER A, BONNIFET JP, REAU R. Gestion de l'azote et fuite de nitrate en terres de groies de Poitou-Charentes. Synthèse des travaux réalisés à la station du Magneraud. Perspectives agricoles $2000 ; 262$ : 44-51.

4. BEAUDOIN N. Caractérisation expérimentale et modélisation des effets des pratiques culturales sur la pollution nitrique d'un aquifère en zone de grande culture. Applications au site de Bruyères. Thèse INA PG INRA, Laon, 2006.

5. MARY B, BEAUDOIN N, JUSTES E, MACHET JM. Calculation of nitrogen mineralization and leaching flow in fallow soil using a simple dynamic model. Eur / Soil Sc $1999 ;$ 50 : 549-66.

6. CARIOLLE M. DEAC Azote : un outil pour diagnostiquer le lessivage d'azote à l'échelle de l'exploitation de polyculture. In : Proceedings of the 64th IIRB Congress. Bruges, Belgique. 26-27 juin 2001.

7. BERTHELIN E. Evaluation de DEAC par rapport aux données expérimentales du Magneraud. CETIOM Grignon, Arvalis Le Magneraud, 2005.

8. SIELING K, KAGE H. N balance as an indicator of $\mathrm{N}$ leaching in an oilseed rape - winter wheat - winter barley rotation. Agric Ecosyst Environ $2006 ; 115: 261-9$.

9. REAU R, GIGANDON C. Les indicateurs de pertes d'azote en systèmes de culture colza-céréales: cas du solde azote apport-export. In : Paris : Rencontres annuelles du CETIOM, 2000 : 18-23.

10. REAU R, GIGANDON C, WAGNER D. Les pertes d'azote dans les systèmes de culture avec colza. Oléoscope $2001 ; 62$ : 19-21.

11. GINGUENEAU H. Evaluation d'une opération Ferti-mieux sur un grand bassin versant du sud des Ardennes: une démarche basée sur I'utilisation d'un modèle de simulation. Mémoire ESA Angers. CETIOM Grignon, 2004. 